UDC 613.6.02

DOI: $10.21668 /$ health.risk/2018.2.10.eng

Read

\title{
ASSESSMENT OF RISK FACTORS WHICH CAUSE EMOTIONAL BURN-OUT IN TEACHERS FROM VARIOUS EDUCATIONAL ESTABLISHMENTS IN MAGADAN REGION
}

\author{
T.P. Bartosh, O.P. Bartosh, M.V. Mychko \\ "Arctica” Scientific Research Center of the Russian Academy of Sciences, Far East Branch, 24 Karl Marks avenue, \\ Magadan, 685000, Russian Federation
}

The authors examined 32 teachers from a natural sciences lyceum, 26 teachers from Magadan vocational schools, and 32 teachers from a boarding school located in Evensk, a remote settlement in Magadan region. The research goal was to assess risk factors which could lead to occupational emotional burn-out syndrome in teachers working in secondary and vocational schools in Magadan region. Emotional burn-out parameters were determined as per V.V. Boiko's "Diagnostics of emotional burn-out" questionnaire; neuropsychic adaptation was measured as per a scale developed by I.N. Gurvich; social frustration was determined as per L.I. Wasserman's technique. The research revealed that "Strain" syndrome phase didn't occur in any group of the examined teachers. "Resistance" phase was the most apparent one as it was just starting to appear. "Depletion" phase was detected only in teachers from a lyceum in Magadan, and it was at the stage of just being formed. This teachers' group also had more apparent specific symptoms as per various burn-out phases against two other examined groups, and this discrepancy was statistically significant. We showed that schoolteachers from Magadan and Evensk were significantly more frustrated with various social functioning spheres and had more apparent problems in their neuro-psychic sphere than teachers from vocational schools $(p<0.05)$. Social frustration and occupational activities make their contribution into disorders in teachers' psychic adaptation. High occupational loads borne by schoolteachers, especially in a lyceum where requirements and educational loads are more serious, make adverse impacts exerted by frustrating factors even worse, and result in disorders occurring in neuro-psychic sphere. Occupational deformation of schoolteachers' personalities deteriorates due to long-term exposure to extreme climatic conditions existing in the North-Eastern regions. Teachers from vocational schools don't run similar risks of occupational burn-out syndrome which can be explained by less strict requirements to educational process in such establishments. North.

Key words: teachers, risk factor, emotional burn-out syndrome, frustration, neuro-psychic adaptation, the

Occupational activities of a teacher involve frequent micro-stresses and neuroemotional strain [1]. Teaching is a peculiar social micro-environment and it is associated with continuous impacts exerted on the nervous system by emotional stressful factors. Teachers often have adverse psy- chic state and it results in their lower working capabilities and poorer health. Issues related to teachers' occupational risks are becoming truly vital at present when the contemporary education system is undergoing major restructuring [2, 3]. When body strain reaches a certain level, multiple

(C) Bartosh T.P., Bartosh O.P., Mychko M.V., 2018

Tatyana P. Bartosh - Candidate of Biological Sciences, Associate Professor, Leading Researcher (e-mail: tabart@rambler.ru; tel.: +7 (4132) 62-90-72).

Olga P. Bartosh - Candidate of Biological Sciences, Researcher (e-mail: olga bartosh@inbox.ru; tel.: +7 (4132) 62-90-72).

Marina V. Mychko - Junior Researcher (e-mail: mychko@mail.ru; tel.: +7 (4132) 62-90-72). 
symptoms of occupational burn-out syndrome occur.

In order to save their energy resources, a lot of teachers resort to various psychological protection mechanisms, and they are doomed to emotional burn-out. According to V.V. Boyko [4], "emotional burn-out is a psychological protection mechanism which a personality creates and which means complete or partial removal of emotions (lowering their energy) as a response to selective psychological traumas". Emotional burn-out makes for deterioration of physical and mental health and causes higher risks of various psychogenic disorders and deadaptation $[3,5,6]$. Burnout was shown to be related to higher risks of cardiovascular diseases including metabolic syndrome, hypothalamo-pituitaryadrenals axis deregulation together with activation of the sympathetic nervous system and sleep disorders [7-10].

Life under severe natural-climatic conditions existing in the North-Eastern Russian regions requires great psychophysiological reserves of a body, causes significant stress in the functional systems, and is an additional factor causing occupational stress emergence in teachers [11]. We proved that teachers in Magadan region tended to suffer from rather high psycho-emotional stress, increased fatigue, weakness, inertia, and nervous processes imbalance [11]. The situation can become even worse due to long-term exposure to social frustrating factors which cause adaptation mechanisms strain and lead to disorders in mental adaptation and lower life quality [12]. Therefore, it is vital to assess social frustration (a person's inability to satisfy his or her social needs) and disorders in social adaptation of people living under severe conditions in the NorthEastern regions as a factor which causes health deterioration. Examination of risk factors which cause teachers' occupational burn-out can help to prevent diseases caused by nervous system overstrain and to provide successful implementation of timely prevention activities [13].

Given all the above mentioned, we thought it interesting to examine risk factors causing health disorders in teachers which were related to their occupational activities; our research objects were teachers living in urban and rural environment in the North-Eastern Russian regions.

Our research goal was to assess risk factors causing occupational emotional burnout in teachers from secondary and vocational educational establishments in Magadan region.

We set the following tasks:

1. To perform comparative examination of symptoms phases and how apparent they were in teachers from various educational establishment in Magadan region.

2. To assess neuro-psychic adaptation and social frustration in teachers from various educational establishments in Magadan region.

3. To examine correlations between neuro-psychic adaptation, social frustration, and emotional burn-out symptoms in teachers from various educational establishments in Magadan region.

Data and methods. We included 3 groups into our examination. The first group comprised 32 teachers from Magadan N.K. Krupskaya's natural sciences lyceum No. 1 (average age was $41 \pm 2.2$, teaching experience was $18 \pm 2.1$ ). The second group was made up of 26 teachers employed at vocational schools No. 3 and No. 7 (accordingly, $44 \pm 2.3$ and $17 \pm 3.3$ ). The third group were 32 teachers from a boarding school located in Evensk (accordingly, $40 \pm 2.1$ and $17 \pm 2.3$ ). Evensk is a settlement in Magadan region located 535 
kilometers to the north of Magadan. It is the most uncomfortable place in terms of natural-climatic and social-economic conditions. The only way to get to the regional center from there is to take a flight on a small plane.

All teachers participated in our research voluntarily; the research was conducted in full conformity with the requirements set forth by biomedical ethics; all the participants gave their informative written consent to it in accordance with established procedures.

To assess risks of occupational emotional burn-out, we applied V.V. Boiko's "Emotional burn-out diagnostics" questionnaire $[4,14]$ based on G. Selye's theory which describes how a stress emerges and develops. Emotional burn-out syndrome (EBS) has three phases in its development; each phase consists of four symptoms. Intensity of each symptom varies from 0 to 30 scores: 9 scores or less mean symptom hasn't formed yet; 10-15 scores mean it is being formed; 16 scores and more mean a symptom has formed. Symptoms with 20 scores and more are predominating for this phase or for the whole syndrome. Each phase can score from 0 to 120: 36 and less scores mean a phase hasn't formed yet; 3760 scores mean a phase is being formed; 61 and more scores mean a phase has formed. The overall scores equal to 108 and less are considered to be low; 109-180, average; 181 and more, high $[4,14]$. We determined neuro-psychic adaptation (NPA) with a scale which included 26 questions and helped to diagnose pre-nosologic subclinical states similar to a neurosis [15]. People who score more than 20 according to this scale suffer from neuro-psychic instability and emerging stress. A technique for determining social frustration (SF) is aimed at detecting zones where the greatest social frustration appears. The higher scores are, the more dissatisfied a person is $[12,14]$.

All the obtained data were processed as per conventional techniques with "Statistica-6.0" software. Sampling distribution which corresponded to a standard one was determined for all the examined parameters; simple mean (M) and error of mean $( \pm \mathrm{m})$ were calculated. We applied Student's t-criterion to test significance of discrepancy between groups. Parameters relationships were detected with Spearmen's rank correlation coefficient.

Results and discussion. Our research results are given in Figures 1-4; they focus on comparison between teachers working in secondary schools and vocational schools in Magadan, and their colleagues from Evensk (a remote settlement in Magadan region) in terms of phases formation and burn-out symptoms intensity.

As we can see from Figure 1, "Strain" phase of the syndrome hasn't formed in all three teachers' groups. "Resistance" phase is the most apparent and it is being formed; it shows that mechanisms of protection against significant expenditure of emotional resources are already functioning.

"Depletion" phase hasn't formed either, excluding teachers from the lyceum (group 1). It is interesting to note, that average values of "Resistance" phase and "Depletion" phase are significantly higher in this group $(\mathrm{p}<0.05)$, than in two others.

If we consider burn-out symptoms intensity in greater details, we can see (Figure 2) that teachers from the lyceum in Magadan suffer from "psychological traumatic experience" in "Strain" phase and this symptom is much more apparent in them against two other groups $(p<0.05)$. These people also have "anxiety and depression" symptom more frequently. In 
other words, they are more aware of occupational factors which cause psychological traumatic experience, such as despair, personal anxiety, disappointment in themselves and their occupation. Teachers from vocational schools are dissatisfied with themselves and an occupation they chose. This parameters is the highest among them $(p<0.05)$ in comparison with two other examined groups (Figure 2). All the other symptoms are, on average, not so apparent. And as for teachers from Evensk, they don't have any formed symptoms in this burn-out phase.

"Inadequate selective emotional response" is a formed symptom detected in teachers from the lyceum in "Resistance" phase. It means they suffer from high emotional instability which is characteristics for teachers' personal profile (Figure 3). "Occupational duties reduction" symptom is also practically formed, and these symptoms are statistically significantly $(p<0.05)$ more apparent among them than in two other groups. "Expansion of emotions saving sphere" is being formed among teachers from groups 1 and 3. "Emotional-moral disorientation" and "occupational duties reduction" symptoms are being formed in teachers from all three examined groups (Figure 3). "Resistance" phases symptoms are being formed in teachers from vocational schools in Magadan and teachers from the boarding school in Evensk except "Expansion of emotions saving sphere" in the former group, and "Inadequate selective emotional response" in the latter one.

We didn't detect any "Depletion" phase signs in teachers (Figure 4). However, teachers from the lyceum stated that "emotional deficiency" symptom was already forming in them. And as we can see, average scores of such symptoms as "emotional deficiency" and "personal detachment or depersonalization" were signifi- cantly more apparent in them $(\mathrm{p}<0.05)$ in comparison with two other groups. Teachers from vocational schools mentioned having "psychosomatic and psychovegetative disorders" significantly less frequently $(p<0.05)$ than their colleagues from Evensk and the lyceum in Magadan.

As a result, we didn't detect any signs of "Strain" or "Depletion" phase in teachers from Evensk and burn-out symptoms in general. However, as regards "Depletion" phase symptoms, "psychosomatic and psycho-vegetative" disorders prevail in them. Average scores for "Resistance" and "Depletion" phases are significantly higher in teachers from the lyceum in Magadan $(p<0.05)$, than in their colleagues from two other groups. Also, specific symptoms of the syndrome are more apparent in them than in teachers from two other examined groups. "Psychological traumatic experience" which is being formed is the most apparent in "Strain" phase $(p<0.05)$. Such symptoms as "inadequate selective emotional response" and "occupational duties reduction" are significantly more apparent and formed in "Resistance" phase $(p<0.05)$; "emotional deficiency" and "personal detachment or depersonalization", in "Depletion" phase $(\mathrm{p}<0.05)$.

Such "Resistance" phase symptoms as "emotional-moral disorientation", "expansion of emotions saving sphere", and "occupational duties reduction" are mainly forming in teachers from Evensk. We also detected "Strain" phase symptom, "psychosomatic and psycho-vegetative disorders", in them. "Dissatisfaction with oneself" symptom of "Strain" phase which was being formed was the most apparent in teachers from vocational schools against their counterparts $(p<0.05)$. "Resistance" phase symptoms, excluding "expansion of emotions saving sphere", were also being formed in them. 


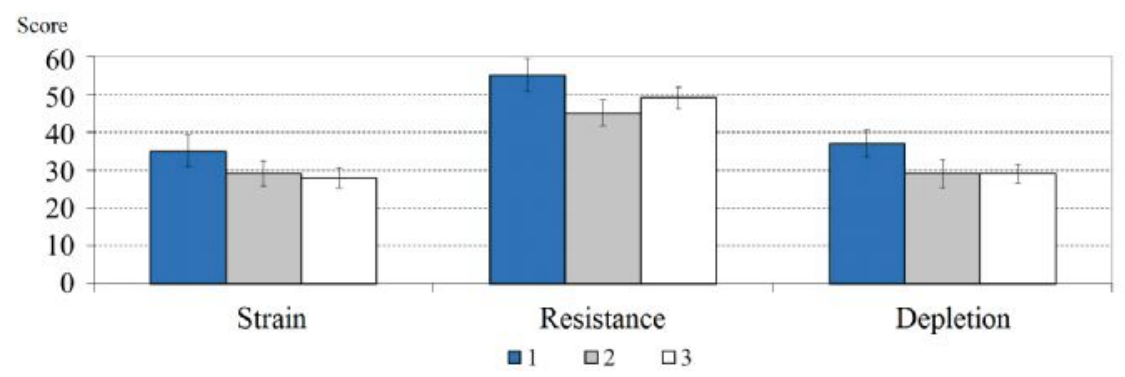

Figure 1. Intensity of emotional burn-out syndrome phases in teachers from 3 different groups:

1 is a group of teachers from a lyceum in Magadan; 2 is a group of teachers from vocational schools in Magadan; 3 is a group of teachers from a boarding school in Evensk

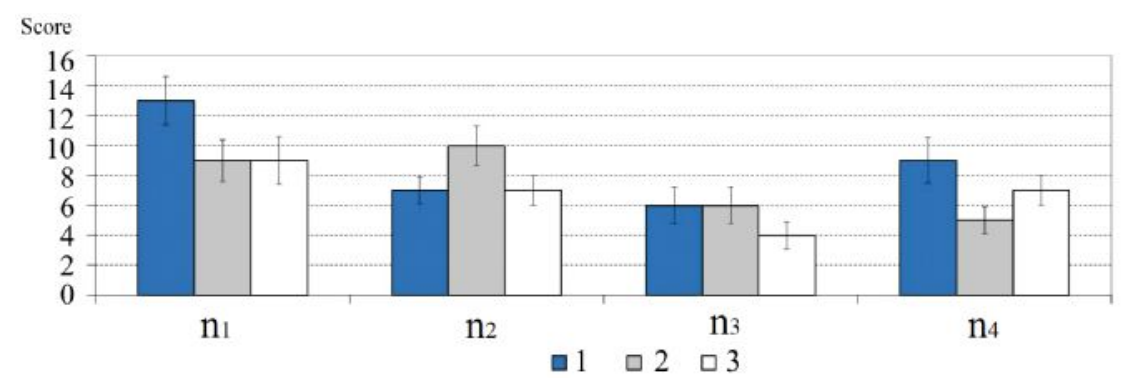

Figure 2. Burn-out symptoms in "Strain" phase in teachers from various groups:

1 is a group of teachers from a lyceum in Magadan; 2 is a group of teachers from vocational schools in Magadan; 3 is a group of teachers from a boarding school in Evensk; $\mathrm{n}$ is "psychological traumatic experience"; $\mathrm{n} 2$ is "dissatisfaction with oneself"; $\mathrm{n} 3$ is "a feeling of being caged"; $\mathrm{n} 4$ is "anxiety and depression"

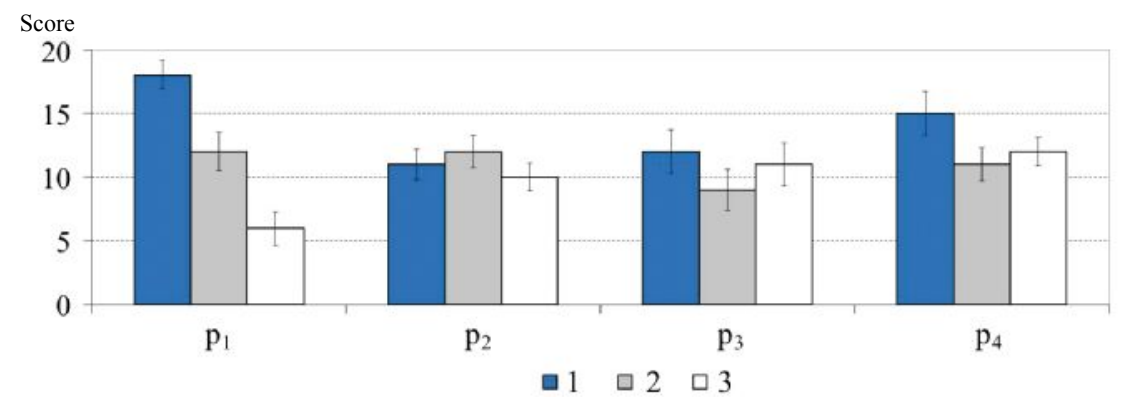

Figure 3. Burn-out symptoms in "Resistance" phase in teachers from various groups:

1 is a group of teachers from a lyceum in Magadan; 2 is a group of teachers from vocational schools in Magadan; 3 is a group of teachers from a boarding school in Evensk; p1 is "inadequate selective emotional response"; p2 is 'emotional-moral disorientation"; p3 is "expansion of emotions saving sphere"; p4 is "occupational duties reduction".

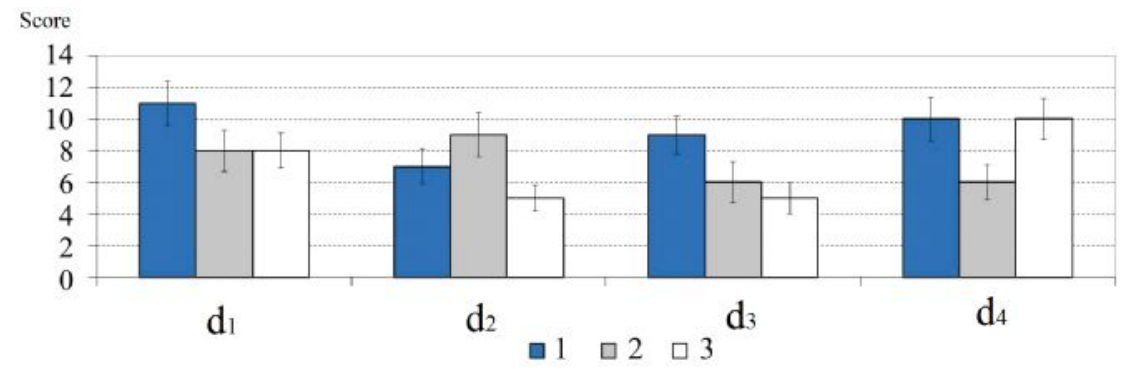

Figure 4. Burn-out symptoms In "Depletion" phase in teachers from various groups:

1 is a group of teachers from a lyceum in Magadan; 2 is a group of teachers from vocational schools in Magadan; 3 is a group of teachers from a boarding school in Evensk; d1 is "emotional deficiency"; $\mathrm{d} 2$ is "emotional detachment"; $\mathrm{d} 3$ is "personal detachment or depersonalization"; $\mathrm{d} 4$ are "psychosomatic and psycho-vegetative disorders". 
We should draw your attention to the fact that teachers from the boarding school located in a remote settlement were to a greater extent exposed to adverse social-economic and natural-climatic conditions of the North-Eastern zone than their colleagues who lived and worked in Magadan. However, teachers working in the lyceum No. 1 in Magadan ran the highest risks of occupational burn-out. In can possibly be due to higher requirements and educational loads in this establishment, that is, due to their direct occupational activities.

When we assessed neuro-psychic adaptation and social frustration of teachers from different educational establishments in Magadan region, we obtained similar results from teachers working in a lyceum in Magadan and a boarding school in Evensk. And their parameters were statistically significantly higher $(p<0.05)$, than in teachers from vocational schools (Figure 5). Individual distribution as per the scale which determines neuro-psychic adaptation (NPA) was within 8-76 scores for teachers from group 1; within 7-36, for teachers from group 2; and 9-39, for teachers from group 3. NPA parameter is a significant criterion which shows socialpsychological adaptation; according to the methodology [15], it corresponded to neuro-psychic instability and limited mental health with apparent signs of stress in teachers from group 1 and 3 . Teachers from vocational schools were, on average, neuro-mentally stable (Figure 5).

Social frustration in teachers from groups 1 and 3 was, on the whole, not apparent, but was statistically significantly higher $(p<0.05)$, than in their colleagues from vocational schools (Figure 5). As a result, teachers from vocational schools seem to be in better conditions as regards neuro-psychic adaptation and social frustration than their colleagues from two other groups.

Analysis of correlations between these NPA parameters and social frustration revealed there was a positive relationship between them in teachers from the lyceum in Magadan $(r=0.63 ; p<0.001)$ and the boarding school in Evensk $(r=0.47$; $\mathrm{p}<0.01)$. We didn't detect any correlations between the above-mentioned parameters in teachers from vocational schools. When frustration occurs, a lot of subcortical masses become active, and significant emotional discomfort appears [12]. Frustrating factors stimulate such responses as aggression and depression which, in their turn, can transfer into selfaggression and fixation of rigid behavioral practices [12]. Therefore increased social frustration in teachers can be a risk factor which causes mental health disorders.
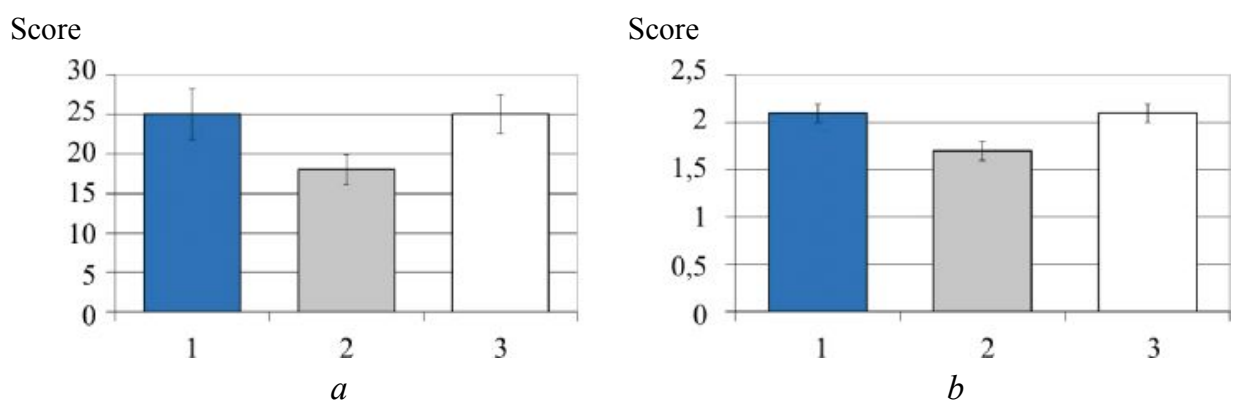

Figure 5. Neuro-psychic adaptation (a) and social frustration (b) in teachers from Magadan region: 1 is a group of teachers from a lyceum in Magadan; 2 is a group of teachers from vocational schools in Magadan; 3 is a group of teachers from a boarding school in Evensk 
We detected positive correlations between parameters of neuro-psychic adaptation, social frustration, and emotional burn-out syndrome. The greatest number of correlations between these parameters was detected in group 1; group 3 followed; the least correlations were detected in group 2.

Neuro-psychic adaptation parameters in teachers from the lyceum in Magadan didn't have any correlation only with "emotional-moral disorientation" and "emotional detachment" out of 15 emotional burn-out syndrome symptoms (correlations within other syndrome parameters were within $\mathrm{r}=0.44-0.69, \mathrm{p}<0.05-0.01) .9$ positive correlations between neuropsychic adaptation parameters and emotional burn-out syndrome were detected in teachers from Evensk; namely, correlations within $\mathrm{r}=0.36-0.74$ range $(\mathrm{p}<0.05-0.01)$ were detected with "Strain" and "Depletion" phases parameters, and such symptoms as "psychological traumatic experience", "a feeling of being caged", "anxiety and depression", "expansion of emotions saving sphere", "personal detachment", and "psychosomatic and psycho-vegetative disorders". The examined parameters had 3 correlations in teachers from vocational schools: neuro-psychic adaptation correlated with "Resistance" phase and such symptoms as "inadequate selective emotional responses" and "psychosomatic and psycho-vegetative disorders" $\quad(\mathrm{r}=0.46-0.62$, $\mathrm{p}<0.05-0.01)$.

Our analysis of correlations between social frustration parameters and emotional burn-out syndrome revealed the following: just as it was with neuro-psychic adaptation, there were no correlations detected in Magadan teachers only with "emotionalmoral disorientation" and 'emotional detachment", while correlations with all the other symptoms were within $\mathrm{r}=0.39-0.66$, $\mathrm{p}<0.05$. As for teachers from Evensk, we revealed 5 statistically significant positive correlations between social frustration parameters and "Strain" phase parameters, "psychological traumatic experience", "a feeling of being caged", "anxiety and depression", and "personal detachment" symptoms $(\mathrm{r}=0.39-0.66, \mathrm{p}<0.05)$. We detected 3 correlations between social frustration and emotional burn-out symptoms in teachers from vocational schools; these symptoms were "dissatisfaction with oneself", "personal detachment", and "psychosomatic and psycho-vegetative disorders" $(\mathrm{r}=0.57-0.68, \mathrm{p}<0.01)$.

At the same time, we detected positive correlation between overall emotional burn-out syndrome scoring and neuropsychic adaptation and social frustration parameters in all the examined groups. We obtained the following values, correspondingly: group $1, r=0.63$ and $r=0.58$; group 2 , $\mathrm{r}=0.45$ and $\mathrm{r}=0.44$; group $3, \mathrm{r}=0.57$ and $\mathrm{r}=0.47$ (at $\mathrm{p}<0.05-0.01)$.

Conclusion. The research revealed that "Strain" phase of the syndrome wasn't formed in all three examined teachers' groups. "Resistance" phase was the most apparent and it was being formed. "Depletion" phase was being formed only in teachers from the lyceum in Magadan. Their average "Resistance" and "Depletion" phases parameters were also significantly higher $(p<0.05)$ than in teachers from two other groups, and specific symptoms as per burn-out phases were also more apparent in them. As a result, teachers from the lyceum in Magadan ran the highest risks of occupational emotional burn-out; teachers from vocational schools were the least susceptible to it. Our research also revealed that teachers from secondary schools in Magadan and Evensk were significantly more frustrated with various spheres of their social functioning and had more apparent problems in their 
neuro-psychic sphere than teachers from vocational schools.

Correlation analysis of all the obtained data revealed that the most strained mechanisms were formed in teachers from school, especially the lyceum in Magadan. It is obvious that social frustration and teachers' occupational activities are basic components in psychic adaptation disorders. Serious occupational loads teachers have to bear, especially in a lyceum where requirements and educational loads are higher make adverse effects exerted by frustrating factors even worse, and make for disorders in neuro-mental sphere, neurotization, and mental deadaptation occurrence. Personal occupational deformation becomes deeper under long-term exposure to extreme conditions existing in the North-Eastern regions. Teachers from vocational schools run lower risks of occupational burn-out syndrome. It is quite possible that requirements to educational process in vocational schools are not so strict as in a natural sciences lyceum.

All the above stated proves it is necessary to perform timely prevention activities in educational establishments as it will help to prevent occupational burn-out syndrome, pathological mental deadaptation, and psychosomatic diseases.

Funding. Our research was not granted any sponsors' support.

A conflict of interests. The authors state there is no conflict of interests.

\section{References}

1. Akhmerova S.G. Professional'naya deyatel'nost' i zdorov'e pedagoga [Occupational activity and health of a teacher]. Moscow, Arsenal obrazovaniya, 2011, 159 p. (in Russian).

2. Valeeva A.S., Davletshina G.R. Professional'nye riski pedagoga v usloviyakh modernizatsii obrazovaniya [Educator"s occupational risks in situation of modernization of education]. Kontekst i refleksiya: filosofiya o mire i cheloveke, 2016, no. 1, pp. 133-144 (in Russian).

3. Ozhegova E.G. Issledovanie osobennostei fizicheskogo i psikhicheskogo zdorov'ya pedagogov [Research on peculiarities of teachers' physical and mental health]. Chelovek $i$ obrazovanie, 2006, no. 8-9, pp. 106-108 (in Russian).

4. Boiko V.V. Energiya emotsii [Energy of emotions]. St. Petersburg, Piter Publ., 2004, 474 p. (in Russian).

5. Maslach C., Leiter M.P. Early predictors of job burnout and engagement. Journal of Applied Psychology, 2008, vol. 93, pp. 498-512.

6. Schaufeli W.B., Leiter M.P., Maslach C. Burnout: 35 years of research and practice. $\mathrm{Ca}$ reer Development International, 2009, vol. 14, no. 3, pp. 204-220. DOI: 10.1108/13620430910966406

7. Shirom A., Melamed S., Toker S., Berliner S., Shapira I. Burnout and health review: Current knowledge and future research directions. International Review of Industrial and Organizational Psychology, 2005, vol. 20, pp. 269-307.

8. Sonnentag S. Burnout research: Adding an off-work and day-level perspective. Work \& Stress, 2005, vol. 19, no. 3, pp. 271-275.

9. Sonnentag S. Burnout and functioning of the hypothalamus-pituitary-adrenal-axis - there are no simple answers. Scandinavian Journal of Work, Environment \& Health, 2006, vol. 32, pp. 333-337. 
10. Melamed S., Shirom A., Toker S., Berliner S., Shapira I. Burnout and risk of cardiovascular disease: evidence, possible causal paths, and promising research directions. Psychol. Bull., 2006, vol. 132, no. 3, pp. 327-353. DOI: 10.1037/0033-2909.132.3.327

11. Bartosh T.P., Bartosh O.P. Psikhofiziologicheskoe sostoyanie i svoistva lichnosti uchitelei Magadanskoi oblasti [The psychophysiological status and personality traits in teachers of the Magadan Region]. Gigiena i sanitariya, 2010, no. 3, pp. 42-46 (in Russian).

12. Vasserman L.I., Shchelkova O.Yu. Meditsinskaya psikhodiagnostika: teoriya, praktika, obuchenie [Medical psychodiagnostics: theory, practice, and training]. St. Petersburg, Akademiya Publ., 2003, 765 p. (in Russian).

13. Nenakhov I.G. Otsenka psikhofunktsional'nogo sostoyaniya sotrudnikov ispytatel'nogo laboratornogo tsentra [Assessment of the psycho-functional state of the employees of the testing laboratory center]. Nauchno-meditsinskii vestnik Tsentral'nogo Chernozem'ya, 2017, no. 70, pp. 151-155 (in Russian).

14. Prakticheskaya psikhodiagnostika. Metodiki i testy [Practical psychodiagnostics. Techniques and tests]. In: D.Ya. Raigorodskii ed. Samara, BAKhRAKh-M Publ., 2011, 672 p. (in Russian).

15. Gurvich I.N. Test nervno-psikhicheskoi adaptatsii [Test to determine neuro-psychic adaptation]. Vestnik gipnologii i psikhoterapii, 1992, no. 3, pp. 46-53 (in Russian).

Bartosh T.P., Bartosh O.P., Mychko M.V. Assessment of risk factors which cause emotional burn-out in teachers from various educational establishments in Magadan region. Health Risk Analysis, 2018, no. 2, pp. 87-95. DOI: 10.21668/health.risk/2018.2.10.eng

Received: 01.06.2018

Accepted: 17.06.2018

Published: 30.06.2018 